\title{
Experimental Study on Fracture Propagation Mechanism of Shale Oil Reservoir of Lucaogou Formation in Jimusar
}

\author{
Jianmin Li, ${ }^{1}$ Yushi Zou $\mathbb{D D}^{2}{ }^{2}$ Shanzhi Shi, ${ }^{1}$ Shicheng Zhang, ${ }^{2}$ Junchao Wang, ${ }^{1}$ Xinfang Ma, ${ }^{2}$ \\ and Xiaohuan Zhang ${ }^{2}$ \\ ${ }^{1}$ Engineering Technology Institute, Petro China Xinjiang Oilfield Company, Xinjiang 834000, China \\ ${ }^{2}$ State Key Laboratory of Petroleum Resources and Prospecting, China University of Petroleum (Beijing), Beijing 102249, China \\ Correspondence should be addressed to Yushi Zou; zouyushi@126.com
}

Received 19 September 2021; Revised 16 January 2022; Accepted 4 February 2022; Published 27 February 2022

Academic Editor: Xiang Zhou

Copyright (C) 2022 Jianmin Li et al. This is an open access article distributed under the Creative Commons Attribution License, which permits unrestricted use, distribution, and reproduction in any medium, provided the original work is properly cited.

\begin{abstract}
The lithology of shale oil reservoir of Lucaogou Formation in Junggar Basin, China shows great variation in a vertical direction and develops bedding planes (BPs). In such formation, rock properties and fabrics have a significant impact on stimulation effects. To clarify the fracture propagation mechanism in a vertically heterogeneous reservoir, an experimental study on fracture propagation in layered rock samples with complex lithology has been conducted. The effect of layers on the height of hydraulic fractures (HFs) was analysed based on triaxial hydraulic fracturing simulation system combined with mineral and mechanical characteristics analysis. The research shows that when the HF is initiated in siltstone layer, it tends to penetrate BPs with the dimensionless fracture height of more than 0.74 . When HF is initiated in mudstone layer, the vertical growth of HFs tends to be terminated at the BPs, and thefracture height is constrained. The greater the thickness of the interlayer is, the more likely the HFs tend to be cut off at the interface and propagate along the interface, resulting in the limited fracture height. Under high horizontal stress difference, HFs are relatively straight. Due to the high permeability of BPs and the low viscosity of fracturing fluid, the fluid leakoff into BPs is observed, which is not conducive to the vertical propagation of HFs. Increasing the viscosity of fracturing fluid facilitates HFs to penetrate the high-permeability BPs and improves the vertical stimulated volume of shale oil reservoir.
\end{abstract}

\section{Introduction}

The shale oil reservoir of Lucaogou Formation in Junggar Basin was deposited in the salinized lake basin sedimentary environment after the closure of residual sea. During the sedimentary period of Lucaogou Formation, the lake basin was in the environment of continuous transformation of deep and shallow water. Due to the influence of structure and climate, the vertical lithology of the reservoir varies greatly in a vertical direction, and the BPs are developed [1-3]. The influence of BPs on HFs propagation behavior and stimulated volume is not clearly understood. Consequently, the selection of fracturing process and engineering parameters mainly lacks theoretical support, and the height of HFs and vertical stimulated volume are limited [4]. Therefore, it is of great significance to study the interaction mechanism between geological interface and HFs and the theory of fracture propagation in a vertical heterogeneous reservoir.

International scholars have conducted a large number of experimental studies on the mechanism of HF propagation [5-9]. The HF propagation behavior in layered rock formations was first studied by Daneshy [10], who found that the HF will penetrate the bonding interface, but the unbonded interface will stop the HF, which is independent of the difference of mechanical properties between the two layers. Wu et al. [11] studied the propagation form of HFs in layered media through plexiglas. It was found that when HFs propagate from rigid media to soft media, the fractures will penetrate the interlayer interface. When the HF propagates from soft medium to rigid medium, the fracture will be cut off or deflected. The fracture mechanics analysis at the interface can be used to judge whether the fracture can penetrate the layer. Athavale and Miskimins [12] used 
cement and sandstone to make layered rock samples to study the fracture propagation dynamics of layered formation. The experiment found that radial HFs were formed in homogeneous samples and complex fractures were formed in thin multi-laminated samples, which were caused by the difference of interlaminar mechanical properties, namely, interfacial shear slippage and strength of the interface. In the experiment, the similarity criteria established by Bunger et al. [13] and Pater et al. [14] were successfully applied, and quasi-static propagating HFs were formed in the laboratory. Heng et al. [15] conducted true triaxial hydraulic fracturing simulation test on shale outcrop, finding that when hydraulic fractures encounter BPs, and observed three types of responses of HFs: (1) stagnation on weak BPs, (2) crossing strong BPs, and (3) deflecting from weak BPs. Whether the HF penetrates through or deflects from the BPs mainly depends on the mechanical properties of BPs. Compared with the shale reservoir deposited in marine environment with stable distribution in North America, the shale reservoir formed in continental environment in China, subjected to complex tectonic movement, was characterized by complex lithology and ample mineral types [16, 17]. Therefore, it is necessary to study the fracture propagation behavior in reservoirs where lithology varies greatly in a vertical direction.

At present, a series of laboratory fracturing experiments on the HF propagation in layered formation have been carried out; however, most of the experiments were carried out on artificial cores and field outcrops, while there were relatively few studies on the HF propagation on the downhole cores of thin-interbedded shale oil reservoirs with BPs. Therefore, it is necessary to further carry out laboratory physical simulation research on thin-interbedded shale oil reservoir to encounter the exploration and development needs of reservoirs with complex geological structure in different blocks in China. Through the XRD analysis and brittleness evaluation of downhole cores, the petrophysical properties of complex lithology were studied to support fracture propagation experiments. After that, a set of true triaxial fracturing simulation experimental devices was applied for fracturing physical simulation experiment with layered samples. Then fracture propagation mechanism of shale oil reservoir of Lucaogou Formation in Jimusar Basin was analysed.

\section{Petrophysical Properties}

2.1. XRD Analysis of Reservoir Rock Samples. The sample was prepared from the downhole core $(10 \mathrm{~cm}$ in diameter) of Lucaogou Formation in Junggar Basin from the same well. Before the fracturing simulation experiment, the mineral composition and basic physical parameters of the rock sample were tested.

The mineral composition of 31 samples was tested. As shown in Figure 1, the main mineral components of shale oil in Lucaogou Formation are quartz and carbonate, with a content of $20 \%$ to $90 \%$. The content of clay minerals, less than $10 \%$, is relatively small. The average content of the main minerals of quartz is $22.44 \%$, plagioclase feldspar $27.38 \%$,

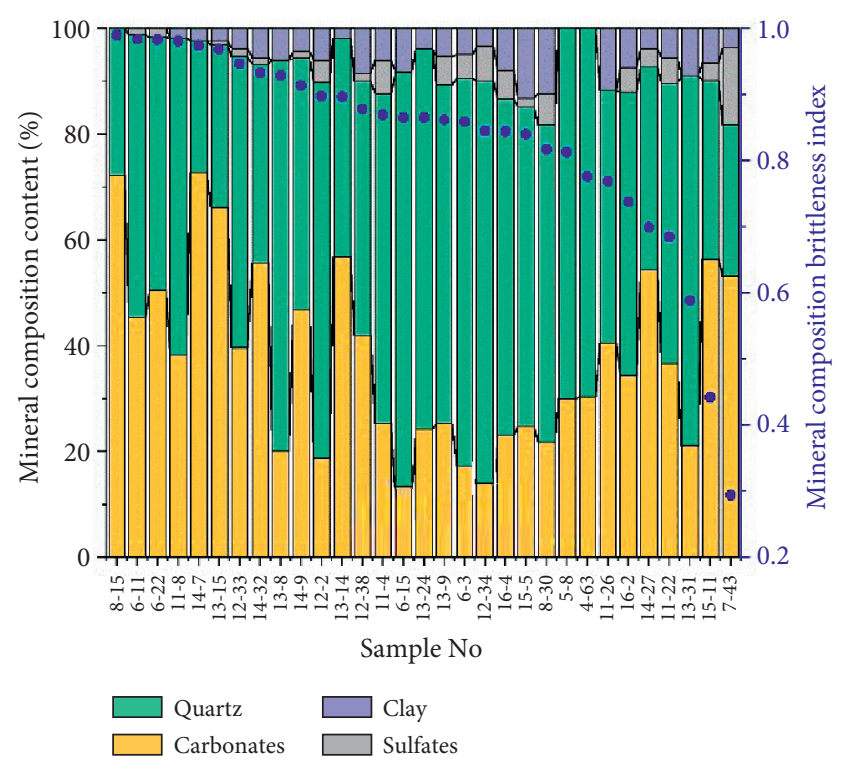

FIgURE 1: Mineral composition and brittleness evaluation results of cores in shale oil reservoir of Lucaogou Formation.

dolomite $28.58 \%$, calcite $10.37 \%$, and clay minerals $5.85 \%$. Based on previous studies [18-21], quartz minerals (quartz, potassium feldspar, and plagioclase) and carbonate minerals (dolomite) are used as brittle minerals to calculate and analyse the brittleness index (formula (1)) of rock mineral composition in shale oil reservoir of Lucaogou Formation in Jimusar Basin.

$$
B_{M}=\frac{m_{\text {qua }}+m_{\mathrm{pf}}+m_{\mathrm{pla}}+m_{\mathrm{dol}}}{m_{\text {total }}},
$$

where $m_{i}$ is the weight fraction of component, $i$ is qua is quartz, pf is potassium feldspar, pla is plagioclase, and dol is dolomite.

The results in Figure 1 show that except for a few cores with higher content of clay minerals and sulfate minerals and a low mineral composition brittleness index, the mineral composition brittleness index of other cores is all higher than 0.6 , with little difference.

\subsection{Brittle Characteristics of Rocks with Different Lithology in} Lucaogou Formation. In order to explore the influence of BPs on rock brittleness, standard cores of $5 \mathrm{~cm}$ in length and $2.5 \mathrm{~cm}$ in diameter were drilled in different directions for the same downhole core. Triaxial compression mechanical tests were carried out for cores in directions parallel and vertical to BPs. The experimental results are shown in Figure 2.

From the stress-strain curve, it can be seen that the micritic dolomite sample (sample \#12-34 vertical core) that is perpendicular to $\mathrm{BP}$ direction presented obvious ductile characteristics. After reaching the peak stress of $130 \mathrm{MPa}$, there is no obvious damage behavior with the increase of strain, and there is no sudden drop in load. The micritic dolomite (sample \#12-34 parallel core) parallel to the BP direction shows strong brittleness characteristics. After reaching the peak stress of $228 \mathrm{MPa}$, fracture appears 


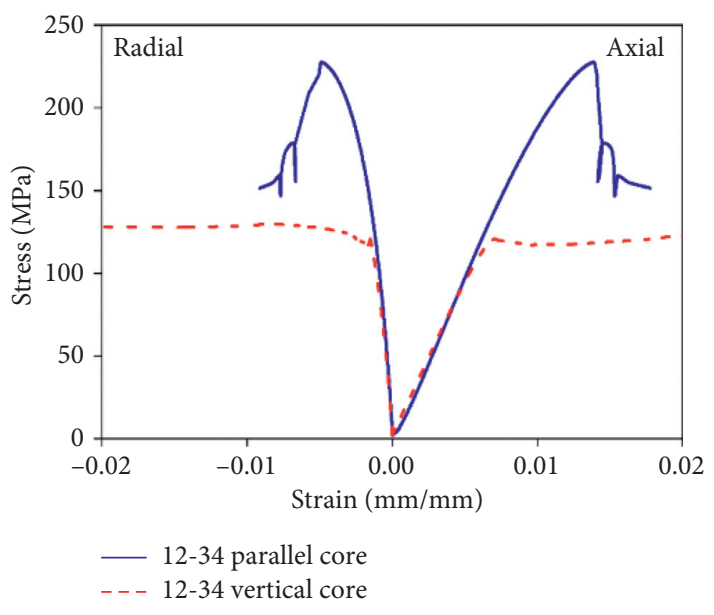

(a)

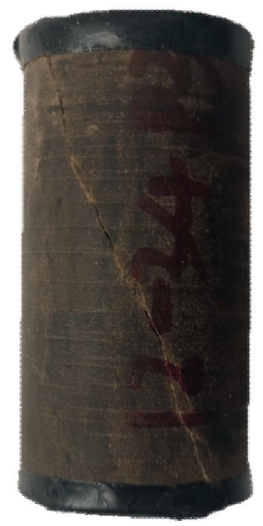

(b)

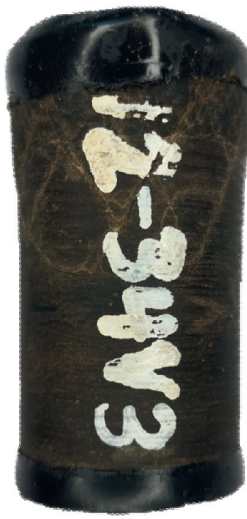

(c)

FIGURE 2: Brittle characteristics of rocks in different BP directions: (a) stress-strain curve; (b) fracture geometry in cores parallel to BP direction; (c) fracture geometry in cores perpendicular to BP direction.

obviously, the loading capacity decreases greatly, the postpeak stress decreases rapidly, and the residual stress is about $150 \mathrm{MPa}$. The vertical core volume strain is $4.19 \times 10^{-3}$, and the parallel core volume strain is $-5.06 \times 10^{-4}$. This indicates that the vertical core occurred plastic deformation and volume compression. Parallel cores produced macroscopic fractures and exhibited volume expansion. From the fracture geometry of rock samples, it can also be found that macro shear fractures appear in the rock samples in the direction parallel to BPs, while the rock samples in the direction perpendicular to BPs show expansion deformation behavior. Based on the energy evolution analysis of full stress-strain curve, many scholars put forward the method that can best reflect the brittle characteristics of rock [22-25]. High brittleness means that the sample stores more absorbed energy in the form of elastic strain energy before the peak, rock failure depends more on the release of elastic strain energy, and the consumption of elastic strain energy is more thorough after the peak value. According to this definition, the brittleness index $B$ (composed of $B_{1}, B_{2}$, and $B_{3}$, formula (2)-(5)) proposed by $\mathrm{Li}$ et al. [26] is used to evaluate the brittleness of rock energy evolution of Lucaogou Formation. The brittleness index for sample (\#12-34 parallel core) in the direction parallel to BPs is 0.67 , and that of sample (\#12-34 vertical core) in the direction perpendicular to BPs is 0.
Comprehensive analysis shows that BPs anisotropy has a great impact on the mechanical properties and brittleness characteristics of rock samples. The brittleness of rock samples in the direction parallel to BPs in the same downhole rock core is greater than that of the samples in the direction perpendicular to BPs.

Prepeak stage: the higher the proportion of input energy stored in the form of elastic properties, the higher the brittleness [26].

$$
B_{1}=\frac{U_{p}^{e}}{U_{p}}=\frac{(1 / 2 E)\left\{\left(\sigma_{p}+\sigma_{c}\right)^{2}+2 \sigma_{c}^{2}-2 \nu\left[2\left(\sigma_{p}+\sigma_{c}\right) \sigma_{c}+\sigma_{c}^{2}\right]\right\}}{\int_{0}^{\varepsilon_{a p}} \sigma_{a} \mathrm{~d} \varepsilon_{a}+\sigma_{c} \varepsilon_{v p}},
$$

where $U_{p}^{e} U_{p}^{e}$ and $U_{p}$ are the elastic strain energy and absorbed energy, respectively; $E$ is the Young's modulus; $\sigma_{p}$, $\sigma_{a}$, and $\sigma_{c}$ are the peak stress, axial stress, and confining pressure; $\varepsilon_{a} \varepsilon_{a}$ and $\varepsilon_{v p}$ are the axial strain and volumetric strain, respectively; $v$ is the Poisson's ratio; $B_{1}$ is prepeak brittleness index.

Postpeak stage: the higher the proportion of released elastic energy in the process of driving rock fracture, the higher the brittleness. $W>0$, class I curve (brittle plastic); $w<0$, class II curve (super brittle) [26].

$$
B_{2}= \begin{cases}\frac{\Delta U^{e}}{W+\Delta U^{e}}=\frac{(1 / E)\left(\sigma_{p}+\sigma_{r}+2 \sigma_{c}-4 \nu \sigma_{c}\right)}{\left(-1 / M_{a}\right)\left[\sigma_{p}+\sigma_{r}+2 \sigma_{c}-4 \sigma_{c}\left(-M_{a} / M_{r}\right)\right]+(1 / E)\left(\sigma_{p}+\sigma_{r}+2 \sigma_{c}-4 \nu \sigma_{c}\right)}, & W>0 \\ 1, & W \leq 0\end{cases}
$$

where $W$ is the extra energy, $\sigma_{r}$ is the residual stress, $M_{a}$ is the axial softening modulus, $M_{r}$ is the radial softening modulus, and $B_{2}$ is postpeak brittleness index. 
Residual stage: the more thoroughly the elastic energy is released, the higher the brittleness [26].

$B_{3}=1-\frac{U_{r}^{e}}{U_{p}^{e}}=1-\frac{\left(\sigma_{r}+\sigma_{c}\right)^{2}+2 \sigma_{c}^{2}-2 \nu\left[2\left(\sigma_{r}+\sigma_{c}\right) \sigma_{c}+\sigma_{c}^{2}\right]}{\left(\sigma_{p}+\sigma_{c}\right)^{2}+2 \sigma_{c}^{2}-2 \nu\left[2\left(\sigma_{p}+\sigma_{c}\right) \sigma_{c}+\sigma_{c}^{2}\right]}$,

where $U_{r}^{e}$ is the residual energy, and $B_{3}$ is the residual brittleness index.

Therefore, the total brittleness index is calculated by the following equation [26]:

$$
B=\frac{3}{\sum_{i=1}^{3}\left(1 / B_{i}\right)}
$$

The brittleness of rocks with different lithology of Lucaogou Formation was calculated based on the stressstrain data obtained from triaxial compression experiment. It can be found in Figure 3 that the reservoir rocks of Lucaogou Formation have strong heterogeneity, and the brittleness of rocks with different lithology has a wide range of variation, including argillaceous siltstone, sandy dolomite, and shale. The average energy evolution brittleness index of pelitic siltstone was 0.77 , dolomitic siltstone 0.68 , mud shale 0.61 , dolomitic mudstone 0.43 , micritic dolomite 0.45 , and sandy dolomite 0.68. Among them, the energy evolution brittleness index of pelitic siltstone, mud shale, and sandy dolomite is higher than 0.6 , dolomitic siltstone and micritic dolomite is medium, greater than 0.5 , and dolomitic mudstone is low, less than 0.5. In order to explore the fracture propagation mechanism of rocks with complex lithology and different brittle characteristics of continental shale oil, the physical simulation experiment of fracture propagation has been carried out.

\section{Physical Simulation Experiment of Fracture Propagation}

3.1. Experimental Apparatus and Preparation of Layered Samples. A set of true triaxial fracturing simulation experimental devices is applied for fracturing physical simulation experiment. The device is mainly composed of liquid supply system, stress loading system, real-time data monitoring and acquisition system, and rock chamber and acoustic emission acquisition system. The experimental device is shown in Figure 4.

Preparation process of fracturing test sample is shown in Figure 5. Firstly, the downhole cores with the diameter of $100 \mathrm{~mm}$ were cut into discs, which then were bonded to form thin-interbedded cylindrical samples by epoxy with the height of $10 \mathrm{~cm}$ (divided into 3 layers: $L_{1}=2 \mathrm{~cm}, L_{2}=6 \mathrm{~cm}$, and $L_{3}=2 \mathrm{~cm}$ ). Finally, the cylindrical sample is cut into $8 \mathrm{~cm} \times 8 \mathrm{~cm} \times 10 \mathrm{~cm}$ cube. At the center of surface with the size of $8 \mathrm{~cm} \times 8 \mathrm{~cm}$, a borehole of $5.3 \mathrm{~cm}$ was drilled with a drill bit (outer diameter of $1.5 \mathrm{~cm}$ ) to place the simulated wellbore. A steel pipe (simulated wellbore) with an outer diameter of $1.3 \mathrm{~cm}$, an inner diameter of $0.6 \mathrm{~cm}$, and a length of $4.3 \mathrm{~cm}$ is cemented in the borehole with epoxy. An open hole section (OHS) with a length of $1 \mathrm{~cm}$ at the bottom of the

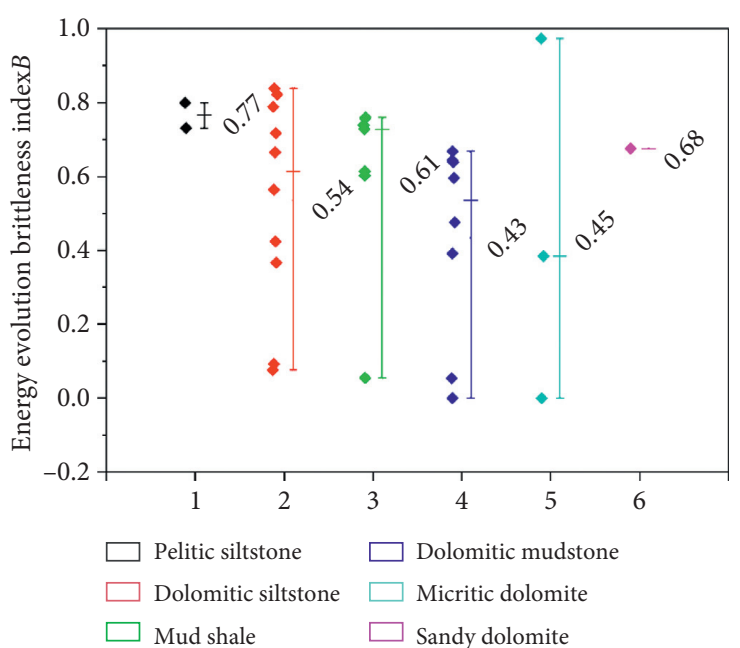

FIGURE 3: Energy evolution brittleness index of rocks with different lithology.

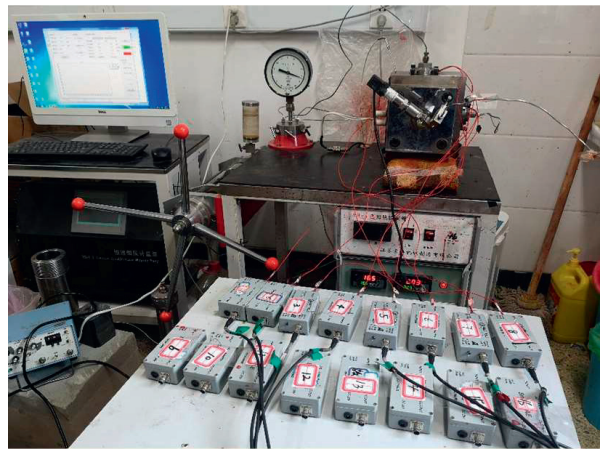

FIgURE 4: Small-size triaxial fracturing simulation system.

well was left unsealed. The standard small-size downhole fracturing physical model is shown in Figure 5(d).

3.2. Experimental Method and Scheme. The minimum horizontal principal stress is applied to simulate the threedimensional in-situ stress state of a vertical well $\sigma_{h}$, maximum horizontal principal stress $\sigma_{H}$ is perpendicular to the shaft axis, and vertical stress $\sigma_{V}$ is parallel to the shaft axis (Figure 5(d)). The fracturing simulation experiment is carried out with the fracturing fluid added with the yellow fluorescent agent to observe the HF geometry. In the process of fracturing simulation, the double-cylinder constant speed and pressure pump is used to inject the fracturing fluid from the intermediate container into the wellbore at a constant injection rate, and the wellhead pressure is recorded by the pressure sensor and transmitted to the computer. When the wellhead pressure drops rapidly and does not increase pressure, it indicates that the HF starts to fracture and extends to the sample surface. At this time, the pump is stopped. After the experiment, the rock sample is taken out, the surface fracture geometry is determined according to the distribution of fluorescent agent solution on the sample surface, and the fracture initiation and propagation 


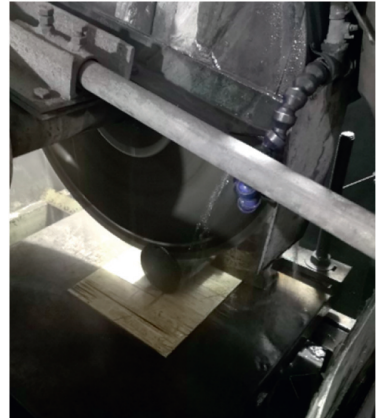

(a)

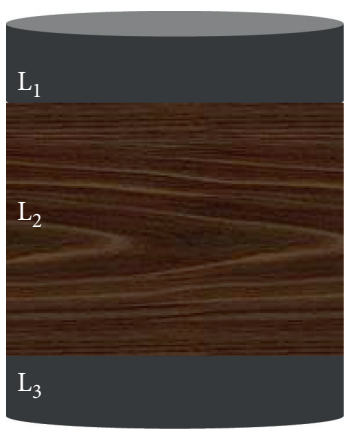

(b)

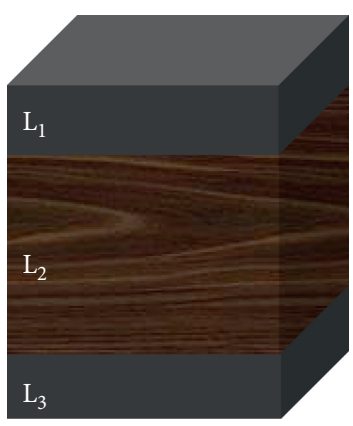

(c)

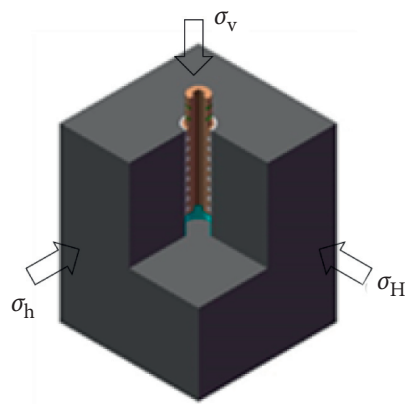

(d)

Figure 5: Fabrication process of small-size model. (a) Cutting discs from downhole cores. (b) Bonding of different lithology. (c) Cutting cylindrical samples into the cube. (d) Drilling and completion.

characteristics combined with the wellhead injection pressure curve are analysed.

The experiment mainly considers the effects of reservoir lithology, interlayer thickness, horizontal stress difference, and fracturing fluid viscosity on HF propagation, and a total of 7 groups of experiments are carried out. Table 1 lists the parameters used during the fracturing experiments.

\section{Experimental Results and Analysis}

4.1. Injection Pressure versus Time Curves Characteristics. Samples 1-3 were the comparison of different lithologies, samples 2 and 4 were the comparison of different horizontal stress differences, samples 5 and 6 were the comparison of different layer thicknesses, and samples 3 and 7 were the comparison of different fracturing fluid viscosities. Figure 6 shows the injection pressure versus time curves during the fracturing experiments. The specific parameters are given in Table 1 When the fluid was injected into the wellbore, the injection pressure increased rapidly from zero with the injection time. The injection pressure then reached a peak value, namely, breakdown pressure. Afterward, the injection pressure decreased sharply, indicating that HF was initiated from OHS. HF continued to propagate at a propagate pressure that fluctuated above and below the minimum horizontal stress $\left(\sigma_{h}=2 \mathrm{MPa}\right)$ until the pump was shut-in. The pressure curve patterns of different experiments were significantly different, especially in terms of pressurization rate and breakdown pressure. These findings will be discussed in the subsequent subsections.

4.2. Influence of Reservoir Lithology Difference. The basic physical property research shows that the mechanical properties of rock samples with different lithology of Lucaogou Formation in Junggar Basin are obviously different $[27,28]$. In this section, the influence of reservoir lithology difference is considered. The rock properties used for the three samples were measured by Triaxial compression test and Brazilian disc test and are listed in Table 2. The lithology of sample \#1 is pelitic siltstone, the lithology of sample $\# 2$ is the combination of silty mudstone in the middle layer and dolomitic siltstone 1 in the interlayer, and the lithology of sample \#3 is the combination of dolomitic siltstone 2 in the middle layer and siltstone in the interlayer.

Under the condition of injection rate of $20 \mathrm{~mL} / \mathrm{min}$, according to injection pressure versus time curves (Figure 6), the breakdown pressure was $8.94 \mathrm{MPa}$ in sample \#1, and the fracture height was $10 \mathrm{~cm}$ (Figure $7(\mathrm{a})$ ), which penetrate the whole sample. In sample \#2, the breakdown pressure was $15.1 \mathrm{MPa}$, and the fracture height was $6.4 \mathrm{~cm}$ (Figure $7(\mathrm{~b})$ ). In sample \#3, the breakdown pressure was $25.6 \mathrm{MPa}$, and the fracture height was $7.4 \mathrm{~cm}$ (Figure $7(\mathrm{c})$ ). The experimental results show that the greater young's modulus and tensile strength of middle layer and interlayer rocks, the greater breakdown pressure of samples. The breakdown pressure of high-strength sample \#3 was 1.86 times greater than that of sample one. Moreover, the greater strength of the rock sample, the higher fluid flow resistance in the fracture of the sample. The propagate pressure was $1.58 \mathrm{MPa}$ in sample \#1, 2.05 MPa in sample \#2, and $4.5 \mathrm{MPa}$ in sample \#3. The propagate pressure was increased by 1.84 times, which was due to the narrow fracture and narrow liquid flow channel of rock with high strength.

Through analysing the local fracture propagation pattern (Figure 8), the influence of BPs on fracture propagation can be observed more intuitively. In the pelitic siltstone of sample \#1, when the BP was activated, the HF directly penetrates the BP. In the silty mudstone of sample $\# 2$, when the HF encounters BP 1 , it activates the BP, turns to propagate along the $\mathrm{BP}$, and then initiates again to continues to propagate along the direction of horizontal maximum principal stress, which soon encounters BP 2. After opening $\mathrm{BP} 2$, it propagates along the horizontal $\mathrm{BP}$ to the boundary and fails to penetrate BP 2. Its width is less than that of sample \#1. The BP opening width in sample \#2 is greater than that of sample \#1. It shows that BPs in mudstone are easier to open and have a greater barrier effect on the vertical propagate of HFs.

In the nonlayered low Young's modulus and lowstrength sample, the fracture starts from the OHS, propagates up and down the wellbore, and penetrates the whole sample, and two horizontal BPs are opened. However, in the high-strength sample, the fracture tends to propagate to the upper part of the wellbore and fails to penetrate the whole 
TABle 1: Parameters used during the fracturing experiments.

\begin{tabular}{lcccc}
\hline Sample number & Layer thickness: $L_{1} / L_{2} / L_{3}(\mathrm{~cm})$ & Injection rate $(\mathrm{mL} / \mathrm{min})$ & Viscosity $(\mathrm{mPa} \cdot \mathrm{s})$ & Horizontal stress difference $(\mathrm{MPa})$ \\
\hline 1 & 10 & 20 & 100 & 13 \\
2 & $2 / 6 / 2$ & 20 & 100 & 13 \\
3 & $2 / 6 / 2$ & 20 & 100 & 13 \\
4 & $2 / 6 / 2$ & 20 & 100 & 18 \\
5 & $3 / 4 / 3$ & 5 & 100 & 13 \\
6 & $2 / 6 / 2$ & 5 & 100 & 13 \\
7 & $2 / 6 / 2$ & 20 & 3 & 13 \\
\hline
\end{tabular}

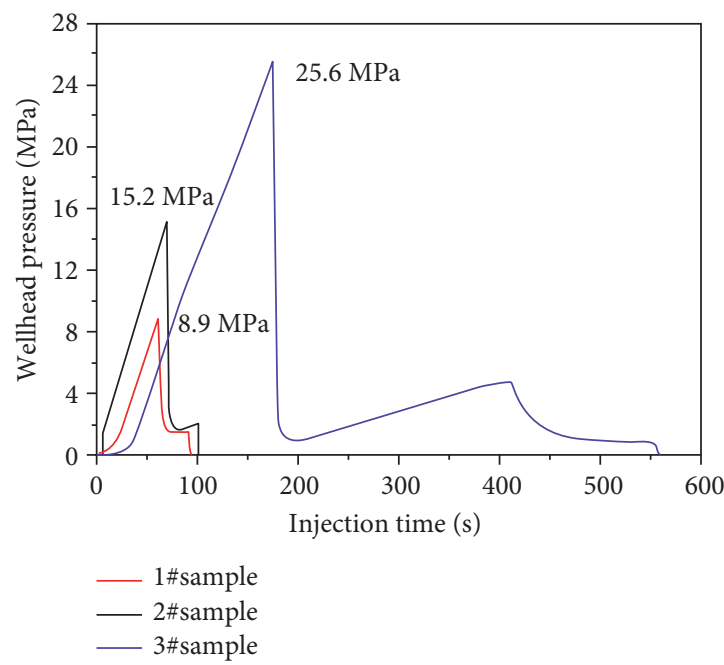

(a)

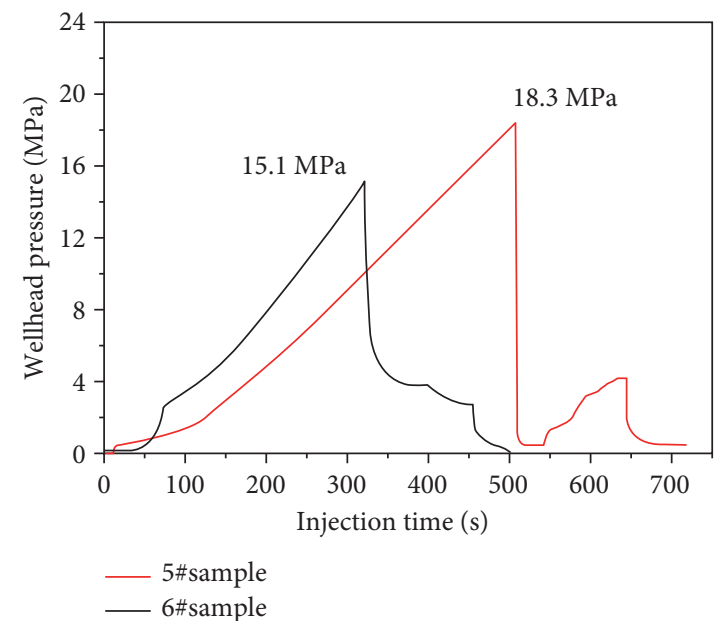

(c)

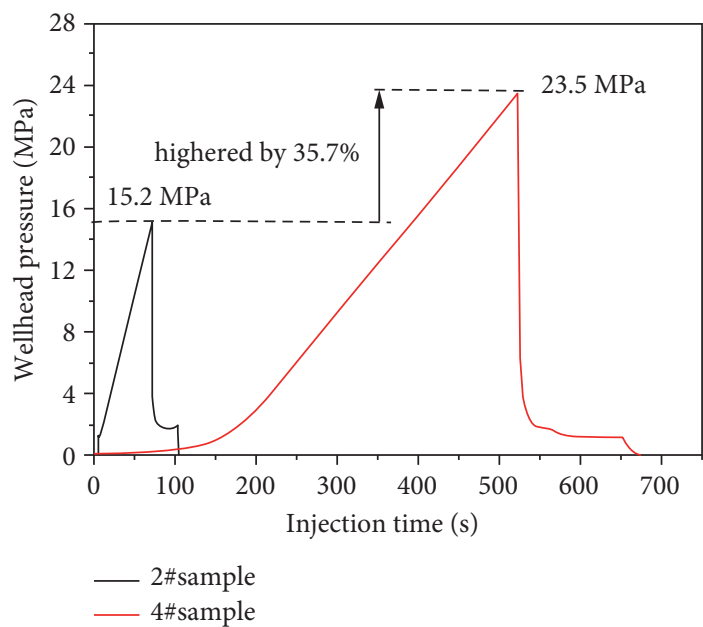

(b)

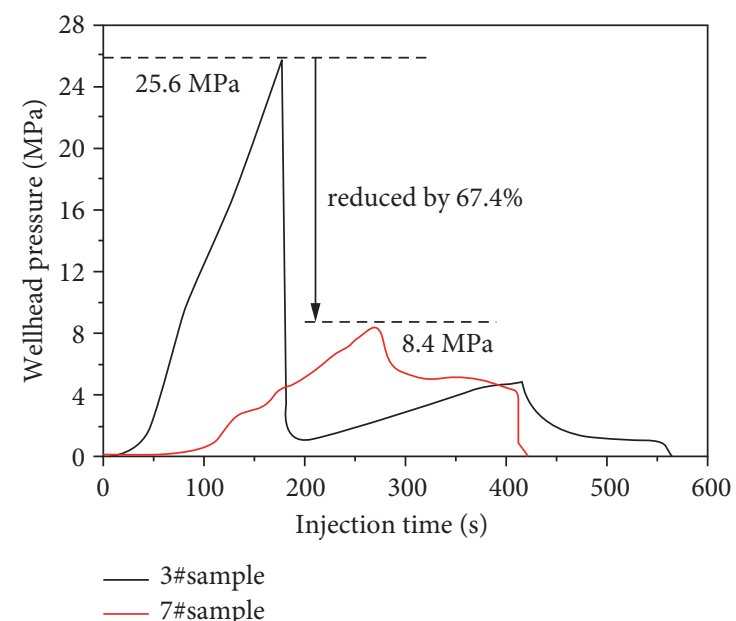

(d)

FIGURE 6: Comparison of injection pressure versus time curves characteristics under different influencing factors. (a) Different lithology; (b) different horizontal stress difference; (c) different layer thickness; (d) different fracturing fluid viscosity.

TABLE 2: Statistical table of downhole rock sample properties.

\begin{tabular}{lcc}
\hline Rock name & Young's modulus $(\mathrm{GPa})$ & Tensile strength $(\mathrm{MPa})$ \\
\hline Pelitic siltstone & 12 & 6 \\
Silty mudstone & 15.64 & 6.49 \\
Dolomitic siltstone 1 & 6.16 & 5.1 \\
Dolomitic siltstone 2 & 20.2 & 6.79 \\
Siltstone & 33.53 & 8.49 \\
\hline
\end{tabular}




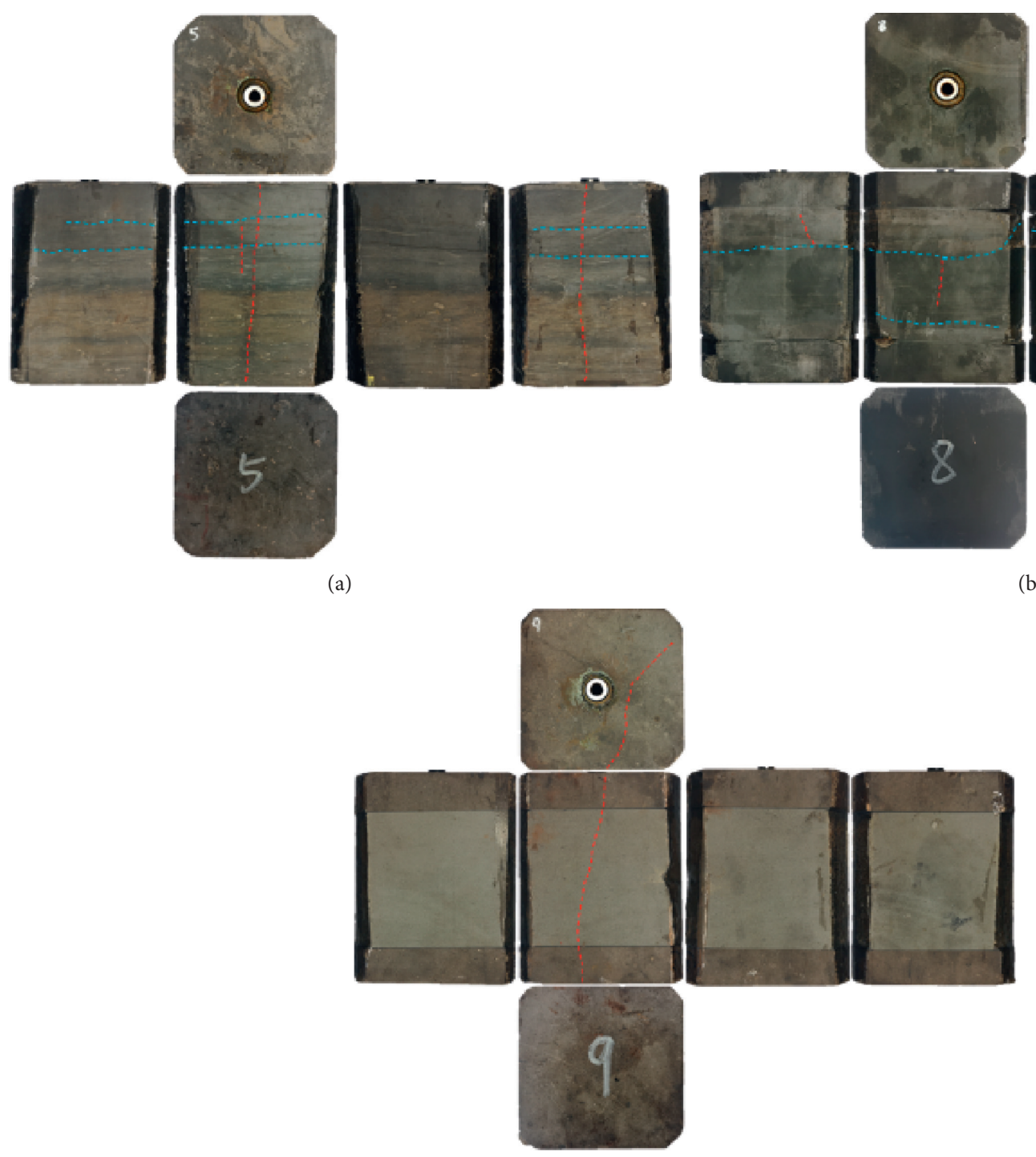

(c)

Figure 7: Fracture geometry and pressure curves of different lithologies. (a) Sample \#1. (b) Sample \#2. (c) Sample \#3.

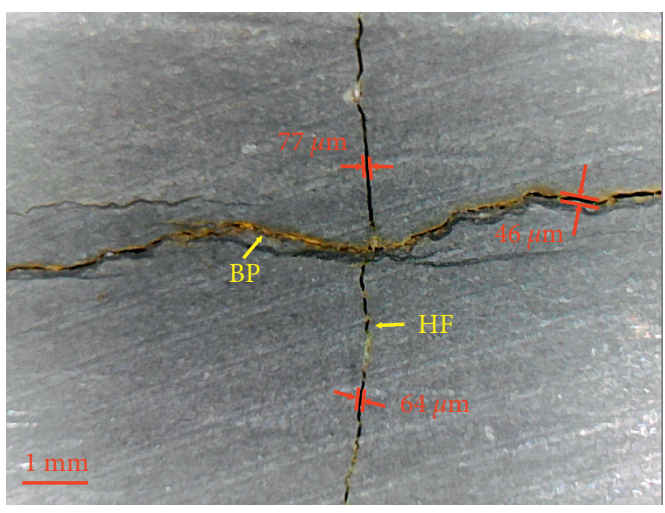

(a)

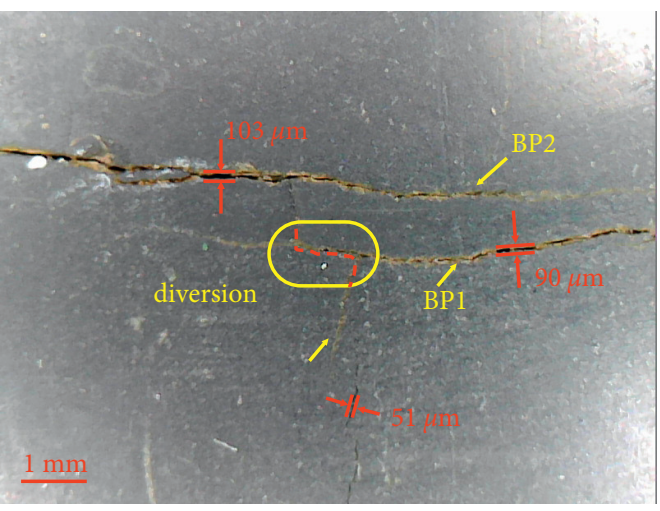

(b)

FIGURE 8: BP propagation behavior of HFs with different lithology. (a) The HF penetrating the BP in sample \#1. (b) HF cutting off by BP in sample \#2. 


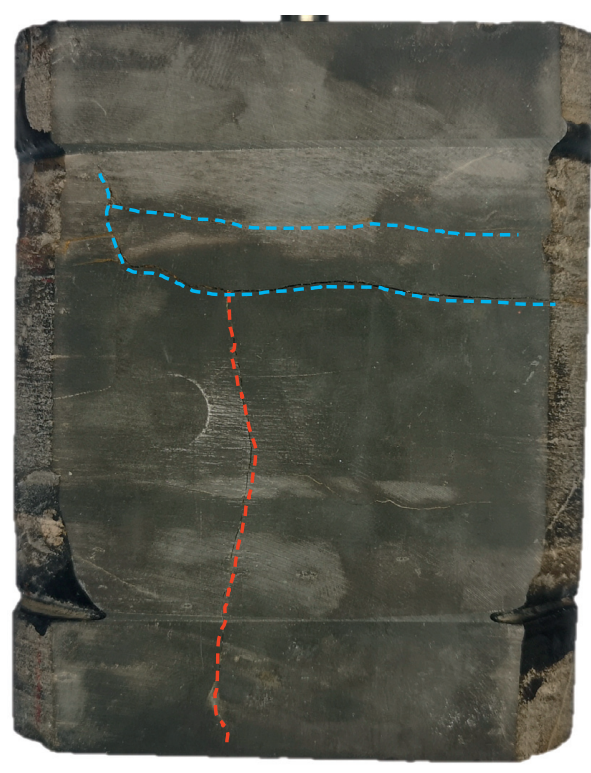

(a)

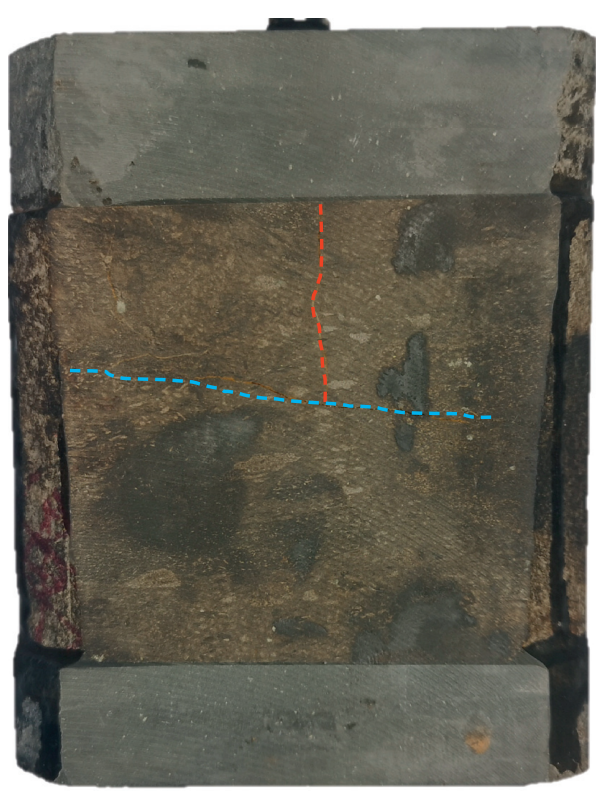

(b)

FIgURE 9: Fracture geometry under different horizontal stress difference. (a) Sample \#2: horizontal stress difference 13 MPa. (b) Sample \#4: horizontal stress difference $18 \mathrm{MPa}$.

sample. The strength increases, and the fracture height shows a downward trend. Without opening the BP, the fractures can penetrate the bonding interface of the reservoir. However, sample $\# 2$ failed to reach the bonding interface of the upper layer due to the propagation between the upper two BPs. When the HF is initiated in argillaceous siltstone, it tends to propagate through $\mathrm{BP}$, and the dimensionless fracture height (HF height/sample height) is higher than 0.74. When HF is initiated in mudstone, the vertical growth of $\mathrm{HF}$ tends to terminate at BPs, and the fracture height is constrained. This is mainly because the BPs of mudstone are more developed and the cementation strength is lower.

4.3. Influence of Horizontal Stress Difference. The horizontal stress difference has an important impact on the complex fracture geometry of natural fracture-developed reservoir. Generally, the smaller the horizontal stress difference is, the easier it is to form a complex fracture network. For the reservoir with well-developed BP and underdeveloped natural fractures, the impact of horizontal stress difference on fracture propagation needs to be further studied. This section analyses the impact of horizontal stress difference on fracture propagation geometry. As shown in Figure 9, under the conditions of injection rate of $20 \mathrm{~mL} / \mathrm{min}$ and viscosity of $100 \mathrm{mPa} \cdot \mathrm{s}$, the breakdown pressure was $15.16 \mathrm{MPa}$ in sample \#2 under the horizontal stress difference of $13 \mathrm{MPa}$, forming an HF with a height of $6.4 \mathrm{~cm}$, opening two horizontal BPs, and penetrating the interface of the lower bonding layer. Under the horizontal stress difference of $18 \mathrm{MPa}$, the breakdown pressure was $20.57 \mathrm{MPa}$ in sample \#4, forming an $\mathrm{HF}$ with a height of $3 \mathrm{~cm}$. The fracture is more straight and fails to penetrate the interface of the upper bonding layer. A horizontal BP is formed in the middle, and the HF was cut off by the BP. The experimental results show that the horizontal stress difference increases, the HF is more straight, the propagation is more difficult, the vertical growth of HF tends to terminate at the interface, and the fracture height is small. The horizontal stress difference increases by $5 \mathrm{MPa}$, the breakdown pressure increases by $35.7 \%$, and the HF height decreases by $37.5 \%$.

4.4. Influence of Interlayer Thickness. The influence of interlayer thickness on the vertical propagation of HFs is still unknown [16]. This section mainly considers the influence of interlayer thickness on fracture geometry. When the thickness of the interlayer is $3 \mathrm{~cm}$, the fracture geometry of sample \#5 is shown in Figure 10(a). The HF fails to penetrate the upper bonding interface, and the fracturing fluid is leaking off from the bonding interface, with a fracture height of $7.4 \mathrm{~cm}$. When the thickness of the interlayer is $2 \mathrm{~cm}$, the fracture geometric characteristics of sample \#6 are shown in Figure 10(b). The HF penetrates through the upper and lower bonding interfaces, penetrates the whole sample, , opens two horizontal BPs in the middle layer, with complex fracture geometry, and the fracture height reaches $10 \mathrm{~cm}$. The pressure curve is shown in Figure 6(c). The breakdown pressure was $15.1 \mathrm{MPa}$ in sample \#5 and $18.28 \mathrm{MPa}$ in sample \#6. There is little difference in the strength of rock samples between the two groups, and the breakdown pressure is similar. The experimental results show that with the increase of interlayer thickness, the HF tends to terminate at the reservoir interlayer interface and propagate horizontally along the interlayer interface, and the fracture height is limited. The interlayer thickness increases by $50 \%$, and the HF height decreases by $26 \%$. 


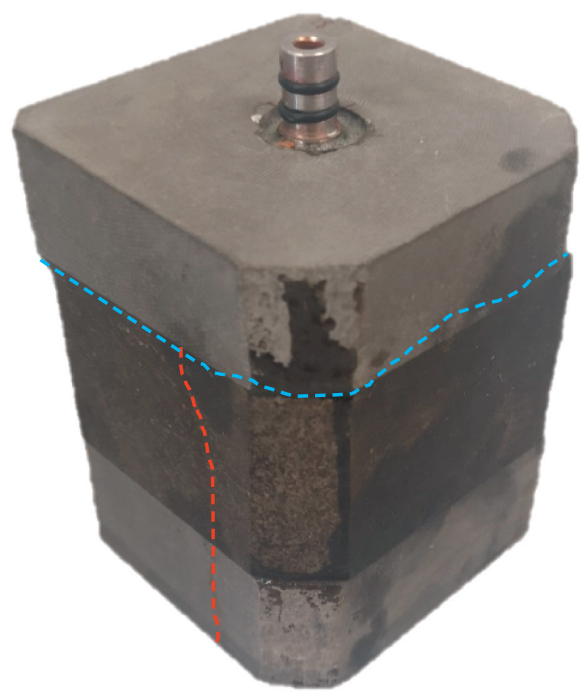

(a)

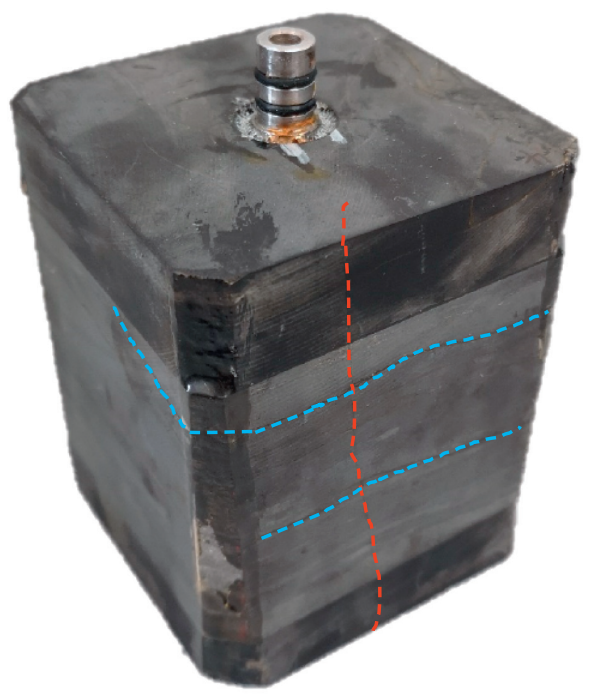

(b)

FIGURE 10: Fracture geometry characteristics of samples with different interlayer thicknesses. (a) Sample \#5. (b) Sample \#6.

4.5. Effect of Fracturing Fluid Viscosity. The performance of fracturing fluid mainly includes frictional characteristics, rheological characteristics, and leakoff. Viscosity can be used as a comprehensive index and is an important physical parameter of fracturing fluid. This section mainly considers the influence of liquid viscosity on fracture propagation. Under the condition of high viscosity of fracturing fluid (100 $\mathrm{mPa} \cdot \mathrm{s})$, the breakdown pressure was 25.59 MPa (Figure 6(d)), the bottom hole pressure growth rate was fast, the breakdown pressure was high, the HF propagated sufficiently vertical and penetrated the bonding interface, and fracture height reached $7.4 \mathrm{~cm}$. Under the condition of low viscosity of fracturing fluid ( $3 \mathrm{mPa} \cdot \mathrm{s})$, the breakdown pressure of the sample was $8.35 \mathrm{MPa}$, which is $67.4 \%$ lower than that of high viscosity fracturing fluid, formed a vertical HF with a height of only $3.1 \mathrm{~cm}$ (Figure 11). A natural BP was activated at the upper and lower parts respectively, and the vertical propagation of the fracture was seriously limited. When the fracturing fluid viscosity was $100 \mathrm{mPa} \cdot \mathrm{s}$, the fracture height increases by 1.39 times compared with the fracturing fluid viscosity of $3 \mathrm{mPa} \cdot \mathrm{s}$.

The experimental results show that the viscosity of fracturing fluid has an important impact on the HF propagation of BP development samples. Due to the strong permeability of $\mathrm{BP}$ and the low viscosity of fracturing fluid, the liquid is easy to leak off along the BP, which is not conducive to the vertical propagate of HFs. Increasing the viscosity of fracturing fluid is helpful for the fracture to penetrate the excessively permeable BP and significantly improve the vertical propagation of fractures. However, under the condition of high viscosity fracturing fluid, HFs are difficult to activate $\mathrm{BP}$, and the fracture geometry is single. In order to improve the fracture control volume, the combined fracturing method of high viscosity fracturing fluid and low viscosity fracturing fluid can be considered.

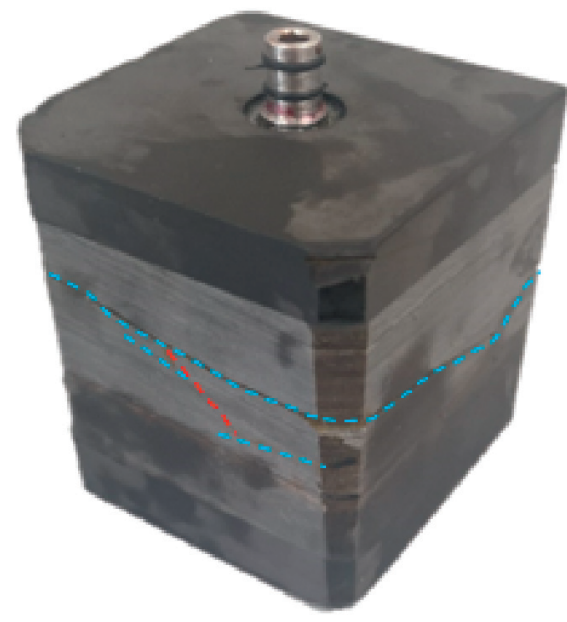

FIgURE 11: Fracture geometry under viscosity $3 \mathrm{mPa} \cdot \mathrm{s}$.

The high viscosity fracturing fluid breaks through the $\mathrm{BP}$ barrier, and low viscosity fracturing fluid activates the BP.

\section{Conclusion}

In this study, the laboratory fracturing simulation experiment was carried out on the downhole core samples of Lucaogou Formation, Junggar Basin, China. Fracture propagation behavior in thin-interbedded rock samples was analysed. The findings are summarized as follows:

(1) In the high-strength sample, HFs tend to propagate to the upper part of the wellbore. The greater the strength is, the smaller the fracture height would be. When HFs initiate in argillaceous siltstone, HFs tend to penetrate BPs, and the dimensionless fracture height is more than 0.74 . When HFs initiate in 
mudstone, the vertical propagation of HFs tends to be terminated at the BPs, and fracture height is constrained.

(2) The greater the thickness of the interlayer is, the more likely HFs tend to be terminated at the interface of the interlayer, propagate along the interface, and have a limited fracture height.

(3) With the increase of horizontal stress difference, the geometry of HF tends to be simple and straight, which is not conducive to the formation of branch fractures.

(4) The viscosity of fracturing fluid has a significant impact on the HF propagation in the BP-developed samples. Due to the high permeability of BP and the low viscosity of fracturing fluid, the fluid filtration occurs along the BPs, which is not conducive to the vertical propagation of HFs. Increasing the viscosity of fracturing fluid facilitates fractures penetrating through the high-permeability BPs.

\section{Data Availability}

The data that support the findings of this study are available on request from the corresponding author. The data are not publicly available due to privacy or ethical restrictions.

\section{Conflicts of Interest}

The authors declare that they have no conflicts of interest.

\section{References}

[1] D. Zhi, Y. Tang, Z. Yang et al., "Geological characteristics and accumulation mechanism ofcontinental shale oil in Jimusaer sag, Junggar Basin,” Oil \& Gas Geology, vol. 40, no. 03, pp. 524-534, 2019.

[2] C. Zou, S. Pan, Z. Jing et al., "Shale oil and gas revolution and its impact," Acta Petrolei Sinica, vol. 41, no. 01, pp. 1-12, 2020.

[3] H. Nie, F. He, and S. Bao, "Peculiar geological characteristics of shale gas in China and its exploration countermeasures," Natural Gas Industry, vol. 31, no. 11, pp. 111-116+132, 2011.

[4] Z. Yang, L. Hou, S. Lin, X. Luo, S. Wu, and J. Cui, "Geologic characteristics and exploration potential of tight oil and shale oil in lucaogou formation in Jimsar sag," China Petroleum Exploration, vol. 23, no. 04, pp. 76-85, 2018.

[5] S. Zhang, T. Guo, T. Zhou, Y. Zou, and S. Mu, "Fracture propagation mechanism experiment of hydraulic fracturing in natural shale," Acta Petrolei Sinica, vol. 35, no. 03, pp. 496-503+518, 2014.

[6] S. Stanchits, J. Burghardt, and A. Surdi, "Hydraulic fracturing of heterogeneous rock monitored by acoustic emission," Rock Mechanics and Rock Engineering, vol. 48, no. 12, pp. 2513-2527, 2015.

[7] Y. S. Zou, S. C. Zhang, T. Zhou, Z. Xiang, and T. Guo, "Experimental investigation into HF network propagation in gas shales using CT scanning technology," Rock Mechanics and Rock Engineering, vol. 49, 2015.

[8] M. Chen, F. Pang, and Y. Jin, "Experiments and analysis on hydraulic fracturing by a large-size trixial simulator," Chinese Journal of Rock Mechanics and Engineering, vol. 19, pp. 868-872, 2000.
[9] J. Zhou, M. Chen, Y. Jin, and G. Zhang, "Experimental study on propagation mechanism of HF in naturally fractured reservoir," Acta Petrolei Sinica, vol. 28, no. 5, pp. 109-113, 2007.

[10] A. A. Daneshy, "HF propagation in layered formations," Society of Petroleum Engineers Journal, vol. 18, no. 1, pp. 33-41, 1978.

[11] H. Wu, A. Chudnovsky, J. W. Dudley, and G. K. Wong, "A map of fracture behavior in the vicinity of an interface," in Proceedings of the American Rock Mechanics Association, Wollongong, Australia, 2004.

[12] A. S. Athavale and J. L. Miskimins, "Laboratory hydraulic fracturing tests on small homogeneous and laminated blocks," in US Rock Mechanics Symposium, Taylor \& Francis, London, UK, 2008.

[13] A. P. Bunger, E. Detournay, and D. I. Garagash, "Toughnessdominated hydraulic fracture with leak-off," International Journal of Fracture, vol. 134, no. 2, pp. 175-190, 2005.

[14] C. D. Pater, M. P. Cleary, T. S. Quinn, D. T. Barr, D. E. Johnson, and L. Weijers, "Experimental verification of dimensional analysis for hydraulic fracturing," SPE Production \& Facilities, vol. 9, no. 4, pp. 230-238, 1994.

[15] S. Heng, X. Liu, X. Li, X. Zhang, and C. Yang, "Experimental and numerical study on the non-planar propagation of hydraulic fractures in shale," Journal of Petroleum Science and Engineering, vol. 179, pp. 410-426, 2019.

[16] H. Jin, J. He, Y. Gao, Y. Dong, D. Xu, and Y. Li, "Difficulties and countermeasures of shale oil development in lucaogou formation of jimsar sag," Xinjiang.Petroleum Geology, vol. 40, no. 04 , pp. 379-388, 2019.

[17] W. Zhao, S. Hu, L. Hou et al., "Types and resource potential of continental shale oil in China and its boundary with tight oil," Petroleum Exploration and Development, vol. 47, no. 01, pp. 1-10, 2020.

[18] D. M. Jarvie, R. J. Hill, T. E. Ruble, and R. M. Pollastro, "Unconventional shale-gas systems: the mississippian barnett shale of north-central Texas as one model for thermogenic shale-gas assessment," AAPG Bulletin, vol. 91, no. 4, pp. 475-499, 2007.

[19] F. P. Wang and J. F. Gale, "Screening criteria for shale-gas systems," Gulf Coast Association of Geological Societies Transcations, vol. 59, pp. 779-793, 2009.

[20] J. Li, "Analysis on mineral components and frangibility ofshales in dongying depression," Acta Sedimentologica Sinica, vol. 31, no. 4, pp. 616-620, 2013.

[21] X. C. Jin, S. N. Shah, J. C. Roegiers, and B. Zhang, "Fracability evaluationin shale reservoirs-an integrated petrophysics and geomechanics approach," in Proceedings of the SPE Hydraulic Fracturing Technology Conference, The Woodlands, Texas, USA, February 2014.

[22] B. Tarasov and Y. Potvin, "Universal criteria for rock brittleness estimation under triaxial compression," International Journal of Rock Mechanics and Mining Sciences, vol. 59, pp. 57-69, 2013.

[23] C. Ai, J. Zhang, Y. W. Li, J. Zeng, X.-L. Yang, and J.-G. Wang, "Estimation criteria for rock brittleness based on energy analysis during the rupturing process," Rock Mechanics and Rock Engineering, vol. 49, no. 12, pp. 4681-4698, 2016.

[24] J. Zhang, A. Chi, Y. W. Li, M. G. Che, R. Gao, and J. Zeng, "Energy-based brittleness index and acoustic emission characteristics of anisotropic coal under triaxial stress condition," Rock Mechanics and Rock Engineering, vol. 51, 2018.

[25] I. Rahimzadeh Kivi, M. Ameri, and H. Molladavoodi, "Shale brittleness evaluation based on energy balance analysis of 
stress-strain curves," Journal of Petroleum Science and Engineering, vol. 167, pp. 1-19, 2018.

[26] N. Li, Y. S. Zou, S. C. Zhang et al., "Rock brittleness evaluation based on energy dissipation under triaxial compression," Journal of Petroleum Science and Engineering, vol. 183, 2019.

[27] K. Xi, Y. Cao, R. Zhu et al., "Rock types and characteristic of tight oil reservoir in permian lucaogou formation, Jimsar sag," Acta Petrolei Sinica, vol. 36, no. 12, pp. 1495-1507, 2015.

[28] J. He, C. J. Okere, G. Su et al., "Formation damage mitigation mechanism for coalbed methane wells via refracturing with fuzzy-ball fluid as temporary blocking agents," Journal of Natural Gas Science and Engineering, vol. 90, 2021. 